\title{
Contrasting habitat use and conservation status of Chinese-wintering and other Eurasian Greater White-fronted Goose (Anser albifrons) populations
}

Xueqin Deng ${ }^{1,2}$, Qingshan Zhao ${ }^{1}$, Junjian Zhang ${ }^{1}$, Andrea Kölzsch ${ }^{3,4}$, Diana Solovyeva ${ }^{5}$, Inga Bysykatova-Harmey ${ }^{6}$, Zhenggang $\mathrm{Xu}^{7}$, Helmut Kruckenberg ${ }^{4}$, Lei CaO ${ }^{1,2^{*}}$ and Anthony David Fox ${ }^{8}$

\begin{abstract}
Background: GPS/GSM tracking data were used to contrast use of (i) habitats and (ii) protected areas between three Arctic-nesting Greater White-fronted Geese (Anser albifrons, GWFG) populations throughout the annual cycle. We wished to demonstrate that the East Asian Continental Population (which winters on natural wetlands in the Chinese Yangtze River floodplain and is currently declining) avoids using farmland at multiple wintering sites. We also gathered tracking evidence to support general observations from two increasing population of GWFG, the North SeaBaltic (which winters in Europe) and the West Pacific (which winter in Korea and Japan) winter mostly within farmland landscapes, using wetlands only for safe night roosts.
\end{abstract}

Methods: We tracked 156 GWFG throughout their annual cycle using GPS/GSM transmitters from these three populations to determine migration routes and stopover staging patterns. We used Brownian Bridge Movement Models to generate summer, winter and migration stopover home ranges which we then overlaid in GIS with land cover and protected area boundary at national level to determine habitat use and degree of protection from nature conservation designated areas.

Results: Data confirmed that 73\% of European wintering GWFG homes ranges were from within farmland, compared to 59\% in Japan and Korea, but just 5\% in China, confirming the heavy winter use of agricultural landscapes by GWFG away from China, and avoidance of farmland at multiple sites within the Yangtze River floodplain. The same GWFG used farmland in northeast China in spring and autumn, confirming their experience of exploiting such habitats at other stages of their annual cycle. Chinese wintering birds showed the greatest overlap with protected areas of all three populations, showing current levels of site safeguard are failing to protect this population.

Conclusions: Results confirm the need for strategic planning to protect the East Asian Continental GWFG population. While the site protection network in place to protect the species seems adequate, it has failed to stop the declines. Buffalo grazing could serve as one simple strategy to improve the condition of feeding habitats at Dongting Lake and Poyang Lake in the Yangtze, where vast Carex meadows exist. In addition, while we warn against pushing

\footnotetext{
*Correspondence: leicao@rcees.ac.cn

${ }^{1}$ State Key Laboratory of Urban and Regional Ecology, Research

Center for Eco-Environmental Sciences, Chinese Academy of Sciences, Beijing 100085, China

Full list of author information is available at the end of the article
} permits use, sharing, adaptation, distribution and reproduction in any medium or format, as long as you give appropriate credit to the original author(s) and the source, provide a link to the Creative Commons licence, and indicate if changes were made. The images or other third party material in this article are included in the article's Creative Commons licence, unless indicated otherwise in a credit line to the material. If material is not included in the article's Creative Commons licence and your intended use is not permitted by statutory regulation or exceeds the permitted use, you will need to obtain permission directly from the copyright holder. To view a copy of this licence, visit http://creativecommons.org/licenses/by/4.0/. The Creative Commons Public Domain Dedication waiver (http://creativeco mmons.org/publicdomain/zero/1.0/) applies to the data made available in this article, unless otherwise stated in a credit line to the data. 
GWFG to winter farmland feeding in China because of the long-term potential to conflict with agricultural interests, we recommend experimental sacrificial, disturbance-free farmland within designated refuge areas adjacent to the Yangtze River floodplain wetland reserves as a manipulative experiment to improve the conservation status of this population in years when natural food sources are limited.

Keywords: Farmland feeding, Habitat use, Migration, National nature reserve, Protected areas, Staging areas

\section{Background}

The Greater White-fronted Goose (Anser albifrons) (hereafter GWFG) has an almost continuous circumpolar Arctic breeding distribution, comprising 11 recognised biogeographical populations numbering an estimated 4.9 million individuals (Fox and Leafloor 2018). Of these populations, only two are showing long-term declines, i.e. those GWFG which winter in the Caspian Sea and Iraq (which are data deficient rather than actually known to be declining) and those which winter in China (Fox and Leafloor 2018). While we presently are not in a position to find out more about the Caspian Sea/Iraq population, considerable effort has been invested in recent years to gather information to better understand the causes of declines among the population of GWFG that winters in China (Zhao et al. 2012; Jia et al. 2016; Deng et al. 2020). This population of GWFG breeds between the Khatanga River and Yana Bay in the Russian Arctic and winters exclusively in the Yangtze River floodplain, where its numbers have fallen from 140,000 in the early 1990s to just over 50,000 by 2020 (Deng et al. 2020).

One hypothesis arising to account for the difference in population trajectories between the populations has been that the GWFG wintering in China are almost exclusively confined to feeding on natural wetlands $\mathrm{Yu}$ et al. 2017), where all wintering waterbirds are generally considered to be suffering from habitat degradation (Fox et al. 2011). Furthermore, since GWFG seem to be sedge meadow specialists here (Zhao et al. 2012), their numbers locally reflect variation in the suitability and extent of such habitat (e.g. Fan et al. 2020). In contrast, the more than 327,000 GWFG of the West Pacific population wintering in Korea and Japan, which breed from Yana Bay to the Bering Strait in Arctic Russia, are currently showing long-term increases, based on monitoring of winter abundance. However, in both these countries, the species has ceased to rely on wetlands for food, rather increasingly shifting to agricultural land to feed on waste rice and grain left in stubble fields after harvest, or on managed grassland and autumn- and spring-sown cereals (e.g. Shimada 2002; Shimada and Mizota (2011), Kim et al. (2016)). Finally, the North Sea-Baltic population breeds in the tundra area westwards from the Khatanga River in Arctic Russia and winters mainly in the Netherlands, Germany and adjacent countries in western Europe and has increased from 50,000 to 75,000 in the 1960 s to over 1,000,000 in 2012 (Fox and Leafloor 2018). Similar to the West Pacific population, the wild geese wintering in Europe have adapted to new sources of food in agricultural landscapes and benefited from the shift of foraging habitat from natural wetlands to farmland during the non-breeding season, where they enjoy higher food intake rates from higher quality dietary items, although they have also undoubtedly profited from the provision of protected areas and restrictions on hunting activity during the last century (Abraham et al. 2005; Fox and Abraham 2017; Fox et al. 2017). These factors increasingly enable geese to meet their daily energy and nutritional needs when feeding on the farmland for shorter periods of time, which likely improves their physical condition (Fox and Abraham 2017) and hence potentially enhances survival rate, and even supports higher reproductive success in one population (Fox et al. 2005).

Despite arguments that Chinese wintering GWFG are "trapped" in natural wetland habitats in contrast to farmland feeding GWFG in Europe and Japan/Korea (Zhao et al. 2018), we lack convincing evidence to support this assertion. For instance, the goose movements studied by Yu et al. (2018) were all from Poyang Lake, so we lack information from other wintering sites. For this reason, we use Global Positioning System (GPS) tracking data from tagged GWFG wintering in Europe, Japan/ Korea and the Yangtze River floodplain to determine the degree to which these three populations forage on farmland throughout their annual cycle along their migratory corridors, but specifically in winter. This enables us to compare between winter habitat use in an objective way, but also to see if GWFG wintering in China utilize farmland in other parts of China during spring and autumn migration staging to further support the hypothesis that their avoidance of farmland in the Yangtze River floodplain is not linked to a lack of experience of foraging on agricultural land but to factors affecting habitat use in those winter quarters. Finally, we use the same data to look at the level of site protection enjoyed by GWFG in the three populations throughout their annual cycle. By overlaying the areas used by tracked birds on protected area boundaries, we explore if differences in these factors could contribute to the three different population abundance trajectories. 


\section{Methods}

\section{Animal capture and GPS-GSM deployment}

From the East Asia Continental population, we captured 68 Greater White-fronted Geese between October and March on their wintering grounds at Poyang Lake $\left(29^{\circ}\right.$ $07^{\prime} \mathrm{N}, 116^{\circ} 16^{\prime} \mathrm{E}$ ) and Chenyao Lake (in Anhui lakes, 30 $54^{\prime} \mathrm{N}, 117^{\circ} 40^{\prime} \mathrm{E}$ ) in the Yangtze River floodplain, China from 2013 to 2017. From the West Pacific population, a further 70 GWFG were caught in July and August during the moulting period in the Chaun $\left(68^{\circ} 53^{\prime} \mathrm{N}, 170^{\circ} 58^{\prime} \mathrm{E}\right)$ and Indigirka Deltas $\left(70^{\circ} 45^{\prime} \mathrm{N}, 151^{\circ} 28^{\prime} \mathrm{E}\right)$ in Russia during the summers of 2017 to 2019. From the North SeaBaltic population, 18 GWFG were caught in their Dutch and German wintering areas and during flightless moult on Kolguev Island in Arctic Russia between 2013 and 2017.

Birds were fitted with a variety of telemetry devices (Druidtech, China 35 g mounted on neckbands, Hunan Global Messenger Technology Company, China, 26 g or $27 \mathrm{~g}$, mounted on neckbands or using back packs, Ornitela, Lithuania, $38 \mathrm{~g}$, mounted on neck bands, E-obs, Germany, 48 g, using back packs, Konstanz University, $35 \mathrm{~g}$, mounted on neck bands, madebytheo, Netherlands, $38 \mathrm{~g}$, mounted on neck bands) providing GPS positions to within $10 \mathrm{~m}$ accuracy via the Global System for Mobile Communications (GSM) and GPRS mobile telephone networks. These devices provided 1 to 288 GPS positions per day, depending on tag capacity and battery conditions (dependent on absorption of solar radiation by the in-built solar panel). Device failure, low battery power levels and signal loss often hindered the accumulation of regular and precise data, especially in winter when day length was short. We therefore only used tracks from which we obtained 1 to 288 fixes per day along the entire length of the migration routes between breeding and wintering areas. These left tracks of sufficient precision to compile 20 complete autumn migration tracks (3 in 2015, 8 in 2016, 5 in 2017 and 4 in 2018) and 23 complete spring migration tracks (3 in 2015, 9 in 2016, 5 in 2017 and 6 in 2018) for the East Asia Continental population; 57 complete autumn migration tracks (23 in 2017, 14 in 2018, and 20 in 2019) and 17 complete spring migration tracks (9 in 2018 and 8 in 2019) for the West Pacific population and 29 complete autumn migration tracks (4 in 2013, 3 in 2014, 3 in 2015, 9 in 2016, and 10 in 2017) and 24 complete spring migration tracks ( 4 in 2014, 3 in 2015, 7 in 2016, and 10 in 2017) for the North Sea-Baltic population (for full details of the individuals involved and their devices, see Additional file 1: Table S1).

To achieve segmentation of movement tracks and identify staging/stopover sites, we followed the methods of Wang et al. (2018) as follows. Firstly, we modified the first passage time method to achieve movement track segmentation using the modified methods of Lavielle (2005), Barraquand and Benhamou (2008), Le Corre et al. (2014) and Edelhoff et al. (2016). Secondly, we identified individual migration/stopover periods and sites by applying the net squared displacement and minimum convex polygon techniques of Mohr (1947) and Bunnefeld et al. (2010). See Wang et al. (2018) for full details. We defined the departure date as the date of the first position when the individual departed from wintering/moulting/breeding sites and was judged by the methods above to have acquired flight status. Arrival date was defined as the date of the first time when the individual was judged to have arrived at wintering or breeding sites, based on the methods above to qualify as non-flight status after a period of flight. A site where an individual bird spent over 2 days for resting and feeding during migration was defined as stopover site (Kölzsch et al. 2016).

\section{Home range estimation}

We defined the kernel areas used most frequently by geese during summer, winter and at staging/stopover sites as derived above. In those areas, then the land cover composition (habitat use) and the degree of nature conservation protected areas (degree of protection) within which these fell were derived.

We used Brownian Bridge Movement Models (BBMM) to calculate home range kernels. This method not only considers each activity center, but also the movement path of the animal, effectively avoiding the unused area between the activity patches as the animal's home range (Bullard 1991; Horne et al. 2007). Compared with other models, the BBMM can more reasonably deal with the problems of spatial autocorrelation and unequal time intervals between fixes. In addition, the parameters within the BBMM model have ecological significance, taking the animal's moving speed and measurement site errors into account (Bullard 1991; Powell 2000).

We applied the BBMM method to generate individual home ranges (50\% Utilization Distribution) of each of the "stationary" segments of each track identified above, including the wintering, summering, and stopover periods during both migration seasons. BBMM was calculated using the "adehabitatHR" package (Calenge 2006) in R 3.6 (Team RDC 2017). To differentiate between nighttime and daytime habitat use, we separated the "stationary" segments by the local time of sunrise and sunset. "Daytime" was defined as the time of GPS points between one hour before sunrise and one hour after sunset and "nighttime" the time of GPS points between one hour after sunset and one hour before sunrise next day. 


\section{Analysis of habitat use}

For all locations in China, we determined land use from the 2015 China Ecological Remote Sensing Survey and Evaluation Data Set $(30 \mathrm{~cm} \times 30 \mathrm{~m}$ accuracy) released by the Chinese Academy of Sciences and the Ministry of Ecology and Environment Department. This data set contains 6 types of Class I land type: Forest, Grassland, Cropland, Wetland, Artificial surfaces and "Other". For the remaining locations outside of China, we used FROM-GLC10 2017 Data Set $(10 \mathrm{~m} \times 10 \mathrm{~m}$ accuracy) created by Tsinghua University (Gong et al. 2019). This system defines 10 types of Class I land Type: Forest, Grassland, Cropland, Water bodies, Wetland, Artificial surfaces, Permanent snow/ice, Shrubland, Bare substrate and Tundra.

We treated level I category 1 "Forest" for the purposes of this investigation including forest and shrubland, category 2 as "Grassland", category 3 as "Cropland", category 4 "Wetland" as natural wetland habitat including water bodies and wetland, category 5 as "Tundra", then combined all other classes into an "Other" category. For the purposes of this analysis we have amalgamated the categories 2 and 3 and treated these as farmland, since most grassland habitats in the temperate zone are grazed pastoral systems.

Because the tracking data of the three populations were gathered at different time intervals, and the data quality was affected by the logger model, weather, battery conditions, and the behaviour of individual geese, the frequency of derived fixes was uneven (ranging from 1 to 288 GPS points per day). For this reason, it was decided that habitat use and degree of protected area coverage needed to be derived from the BBMM estimated home range delineation rather than of individual points. Thus, for each population, we extracted the land use type within each home range, and then calculated the percentage of land use cover shown in Table SX2. All above processes were extracted using ArcGIS 10.6 (ESRI 2013) and the calculations were run in R 3.6 (Team RDC 2017).

\section{Conservation status at national level}

To estimate the contribution of current conservation of the three GWFG populations by protected areas, we calculated the percentage of the home ranges which fell inside designated protected areas during each phase of the life cycle (summer, winter, and stopover periods during both spring and autumn migration episodes). The national nature reserve (NNRS) boundaries from the Resource and Environment Data Cloud Platform (http:// www.resdc.cn/) were used to define the protected sites inside China (outside Russia), and the boundaries of the protected areas in all other areas were derived from the
World Database on Protected Areas (https://www.prote ctedplanet.net/).

\section{Results}

Migration routes and stopover sites distribution

GWFG from the North Sea-Baltic population migrated between their wintering grounds in western Europe and the summer quarters in the western Russian Arctic in a relatively broad front during the spring migration season. This leads to the stopover sites being widely spread throughout several European countries (Fig. 1). In contrast, the spring migration corridors for both eastern Asia GWFG populations were relatively narrow. Tagged birds from the East Asia Continental population migrated between their wintering grounds in the Yangtze River floodplain and eastern Arctic Russia with relatively concentrated stopover sites in the Songnen Plain in Northeast China (Fig. 2), and some along the Lena River where GWFG migrated in "sickle" shape along Lena River to bypass the Verkhoyansk Mountains (Fig. 1). The West Pacific GWFG population generally migrated between wintering grounds in Korea and summering quarters in the tundra to the East of Yana Bay in Russia. These birds used relatively concentrated stopover sites in the Sanjiang Plain in Northeast China and some scattered areas along the lowlands associated with the Kolyma River (Fig. 1).

During autumn migration, almost all tracked geese from the three populations migrated in a much more direct fashion than in spring, flying from the summering grounds to the wintering resorts along relatively straight paths with fewer stopovers (Fig. 3). Among those tracked from the North Sea-Baltic population, most individuals stopped in the Nenetsky Okrug for a relatively long period, then migrated non-stop through central Europe during day and night, to arrive in the winter quarters. Similarly, a few of the tagged individuals from the West Pacific population stopped in the Kolyma River lowlands shortly after departing from the summering areas, staying there for mostly less than 7 days. Most then flew over the Sea of Okhotsk, some directly to the wintering grounds, while others choose to stop in the Northeast Plain of China for several weeks before continuing to the wintering grounds. Almost all of the birds of the East Asia Continental population migrated non-stop from their summering grounds to stopover sites in Northeast China, and continued after a few weeks of stopover to the wintering grounds in the Yangtze River floodplain, China.

\section{Habitat use}

In summer, the tracked GWFG from all three populations almost exclusively occurred on natural tundra and wetland habitats during daylight hours (Fig. 4 and Additional file 1: Table S2). Furthermore, they all used less than 


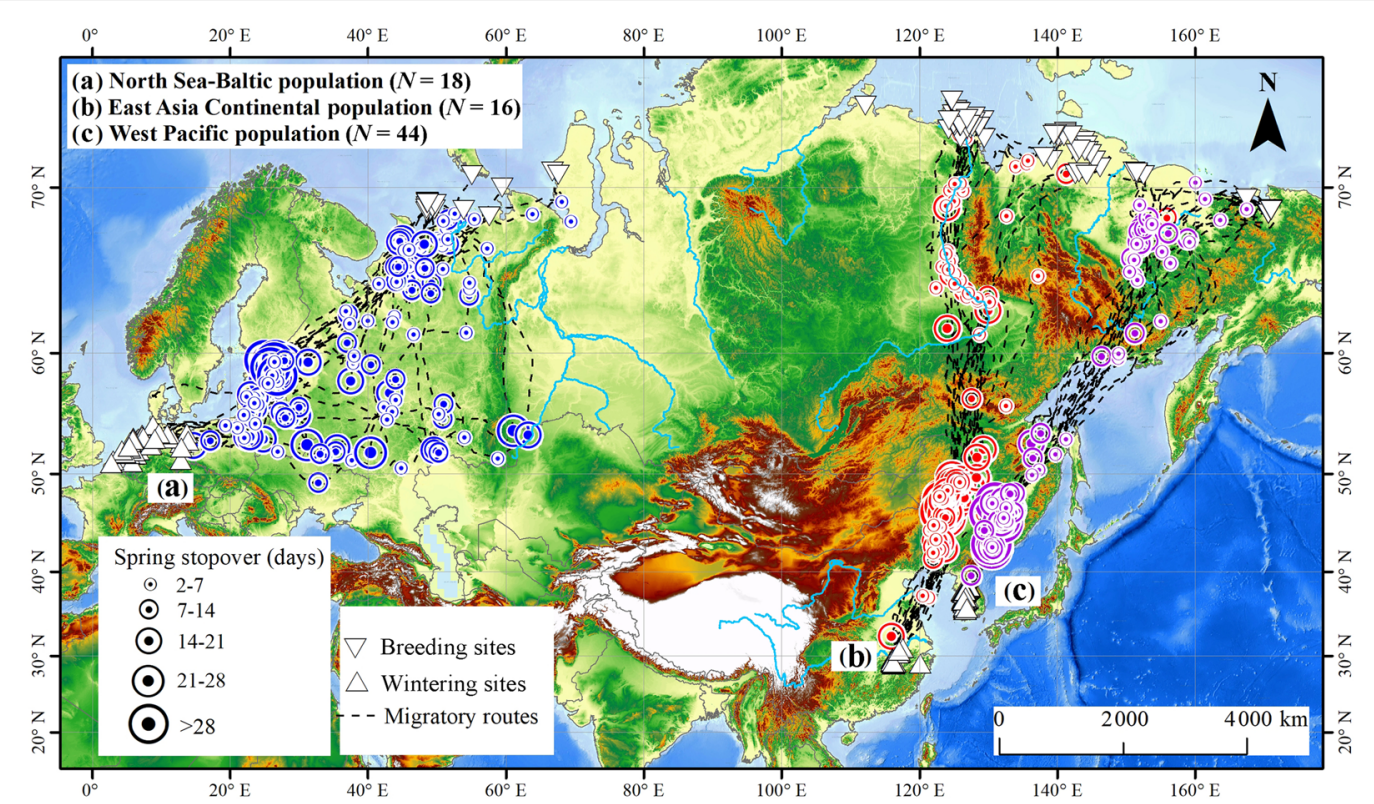

Fig. 1 The spring migration map generated from three tagged Greater White-fronted Geese (Anser albifrons) populations fitted with solar-powered GPS/GSM telemetry devices in Eurasia during 2013-2019. The black dotted line represents the migration route of each tracked individual, the circle with dots represent the stopover sites (blue represents the North Sea-Baltic population $(N=18)$, red represents the East Asia Continental population $(N=16)$, purple represent the West Pacific population $(N=44))$, and the size of the dot represents the stopover duration of each bird in that site. The equilateral triangle represents the wintering sites, the inverted triangle represents the summering sites. The base map is an elevation rendering

$25 \%$ farmland (i.e. grassland and cropland combined) in autumn within Russia (identified as "inRus" in the tables) and $59-73 \%$ farmland outside of Russia (labelled "outRus" in the tables), including those birds from the East Asia Continental population (Fig. 4, Additional file 1: Table S2). As expected, while $71 \%$ of the defined winter home ranges of tagged geese from the North Sea-Baltic population and 59\% from the West Pacific population fell within farmland areas, only $5 \%$ of Chinese wintering GWFG from the East Asia Continental population were registered on farmland. 92\% of their Chinese wintering home ranges fell within the Yangtze River floodplain wetlands (Fig. 4, Additional file 1: Table S2). By comparison, $5 \%$ and $15 \%$, respectively of the home ranges of GWFG from the North Sea-Baltic and West Pacific populations fell within wetlands during the course of the winter. During spring migration, $58-66 \%$ of the home ranges from all three populations were registered in farmland areas while outside of Russia, and between 15\% (East Asia Continental population) and 57\% (North Sea-Baltic population) of area were registered on farmland inside Russia (Fig. 4, Additional file 1: Table S2). Note that although the geese from the East Asia Continental population use farmland during autumn and spring migration, they do not in winter. Furthermore, GWFG from all populations used farmland to a lesser degree at night, similarly across all seasons (Fig. 5, Additional file 1: Table S3).

\section{Conservation status of sites used by GWFG}

Ironically, the overall degree of protection directed towards GWFG from the North Sea-Baltic population (the most numerous and the population showing the most dramatic growth in abundance) was the lowest of all three populations ( $28 \%$, Table 1$)$. The proportion of home ranges in protected areas during all stages within Russia was relatively low (summer: $23 \%$, autumn: $10 \%$, spring: 7\%), but that was also the case outside of Russia (in spring reaching 25\%, autumn $40 \%$ ). In winter, only $27 \%$ of home ranges of tagged individuals fell within protected areas by day (perhaps not surprising given much of these areas are within intensive farmland), rising to $38 \%$ at night, suggesting the roost sites are slightly better protected (Table 2).

In contrast to the western European population, the proportion of East Asia Continental GWFG home ranges that fell within protected areas was relatively high throughout the annual cycle ( $40 \%$ overall) (Table 1$)$. This proportion was especially high during the summering period (67\%), but also at spring stopover areas in Russia (53\%) and on the Chinese wintering areas (52\%). By comparison, the proportions falling in protected areas were lower in autumn (32\%) and spring stopover periods (25\%) in northeastern China.

The proportion of Western Pacific GWFG home ranges overlapping with protected areas was relatively low 


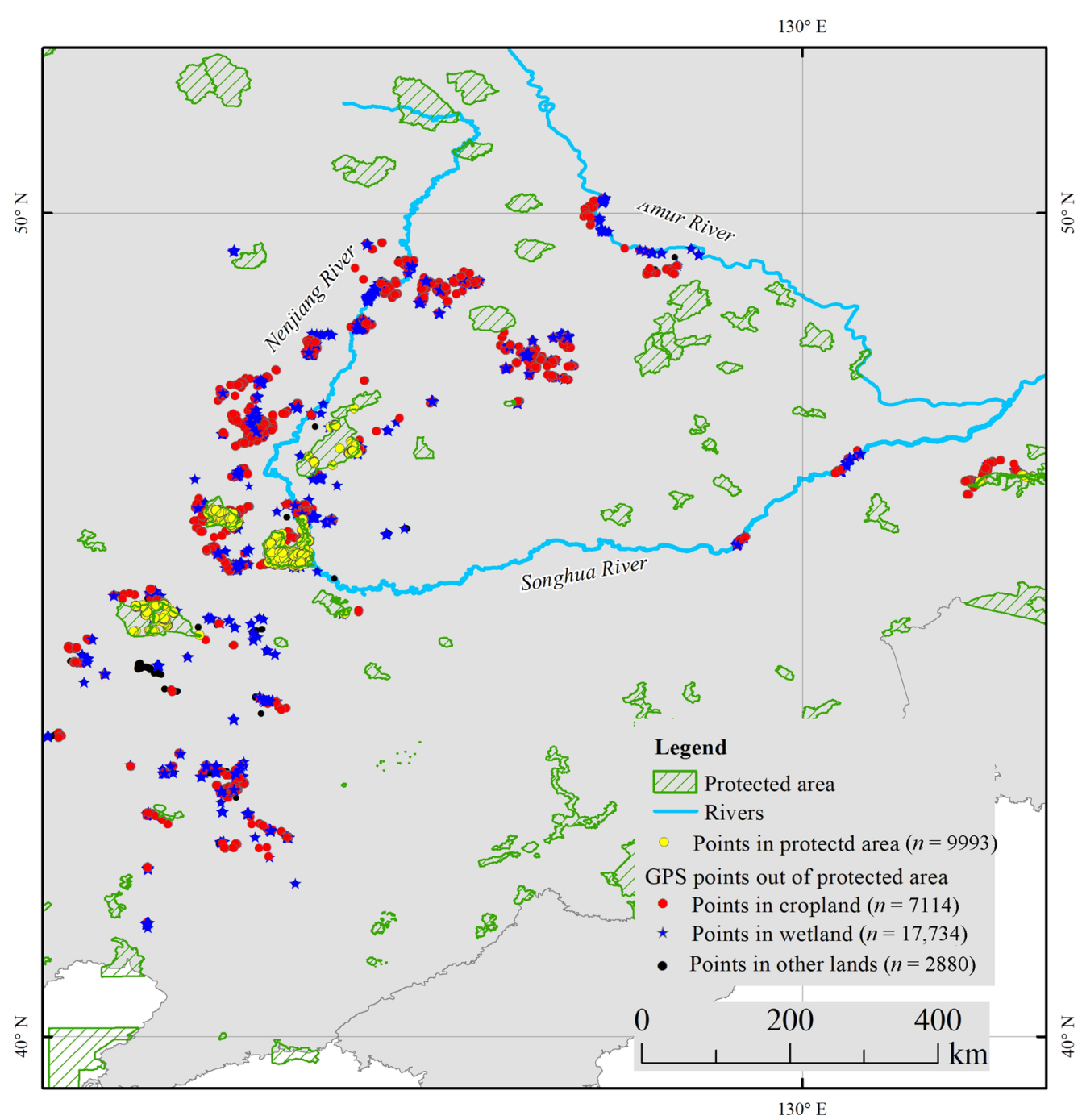

Fig. 2 The GPS fixes of 16 tagged eastern GWFG in the Northeast China stopover area (the main stopover area during spring and autumn migration). The area cross-hatched in green is protected area at national level, the yellow dots were GPS points inside the protected area, other shapes were outside the protected area, the red dots were in croplands, the dark blue stars were in wetlands, and the black dots were in other land types (the 2015 China Ecological Remote Sensing Survey and Evaluation Data Set based on $30 \mathrm{~m} \times 30 \mathrm{~m}$ grid cells)

(34\% overall, Table 1), falling to almost nothing (1\%) in the autumn Russian stopover areas. The proportions of spring stopover home range areas in Russia and on the winter quarters were also not high $(17 \%$ and $19 \%$ respectively), although they rose to $61 \%$ and $43 \%$ in autumn and spring stopover areas outside Russia, respectively higher than that of the other two populations.

\section{Discussion}

The results of this comparison of tracking studies unsurprisingly confirm that on the Russian summering areas, tagged GWFG from all three populations almost exclusively used natural habitats (tundra and wetlands). In winter, tracking data of the same individuals confirmed that the majority of the daytime GWFG home ranges from the North Sea-Baltic (73\%) and West Pacific populations (59\%) were on farmland, compared to $5 \%$ for the East Asia Continental population individuals wintering in China. In contrast, $92 \%$ of daytime registrations of the East Asia Continental population GWFG were from wetlands (96\% at night) compared to 5\% (day) and $14 \%$ (night) for North Sea-Baltic and 15\% and 40\% for West Pacific populations, respectively. Thus, our tracking data in combination with land-use cover confirm that GWFG 

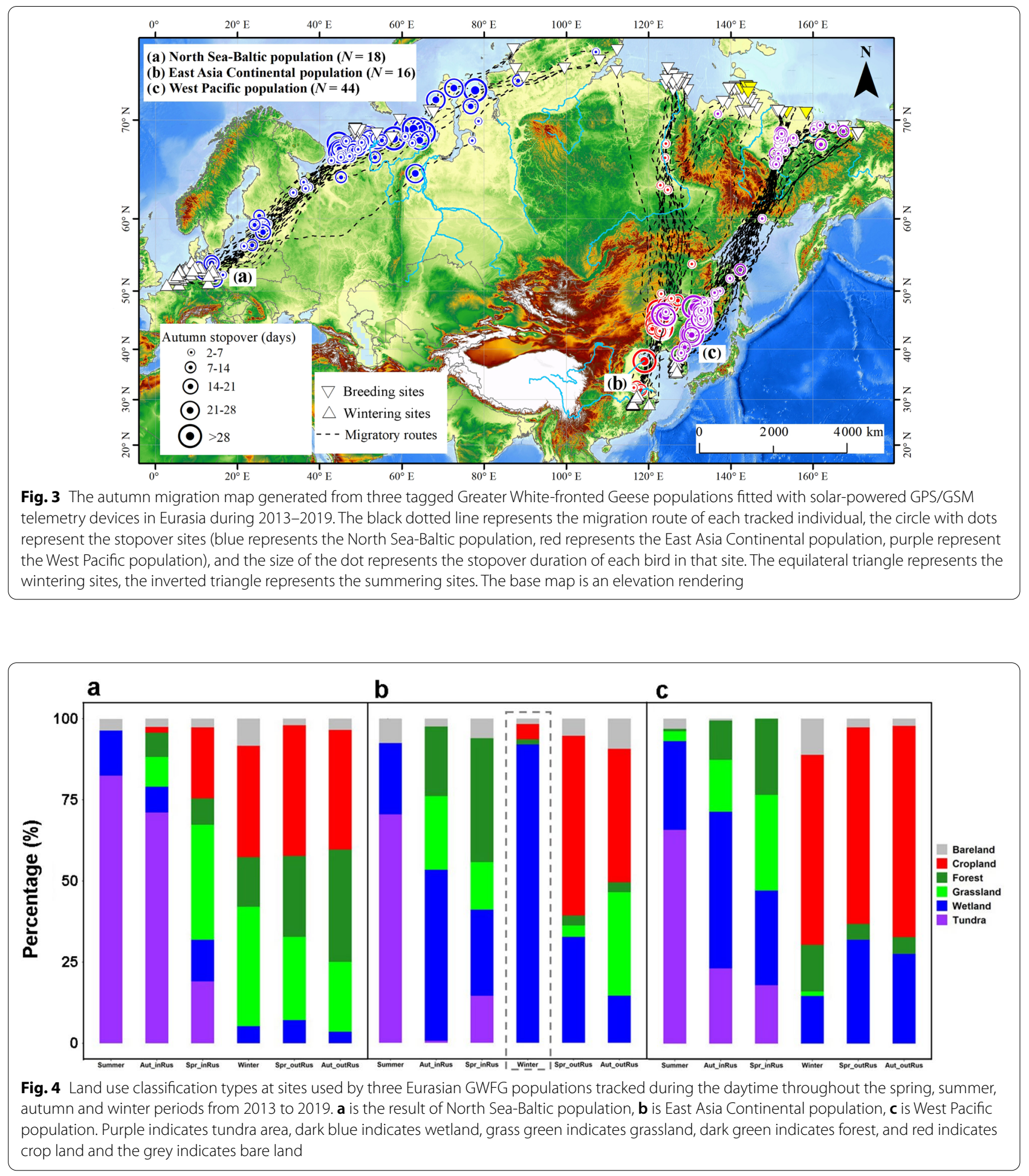

wintering in western Europe and Korea mainly feed on

farmland (and spent a longer proportion of their nights on wetland roosts), even though this was stated to generally be the case (e.g. Kim et al. 2016). 


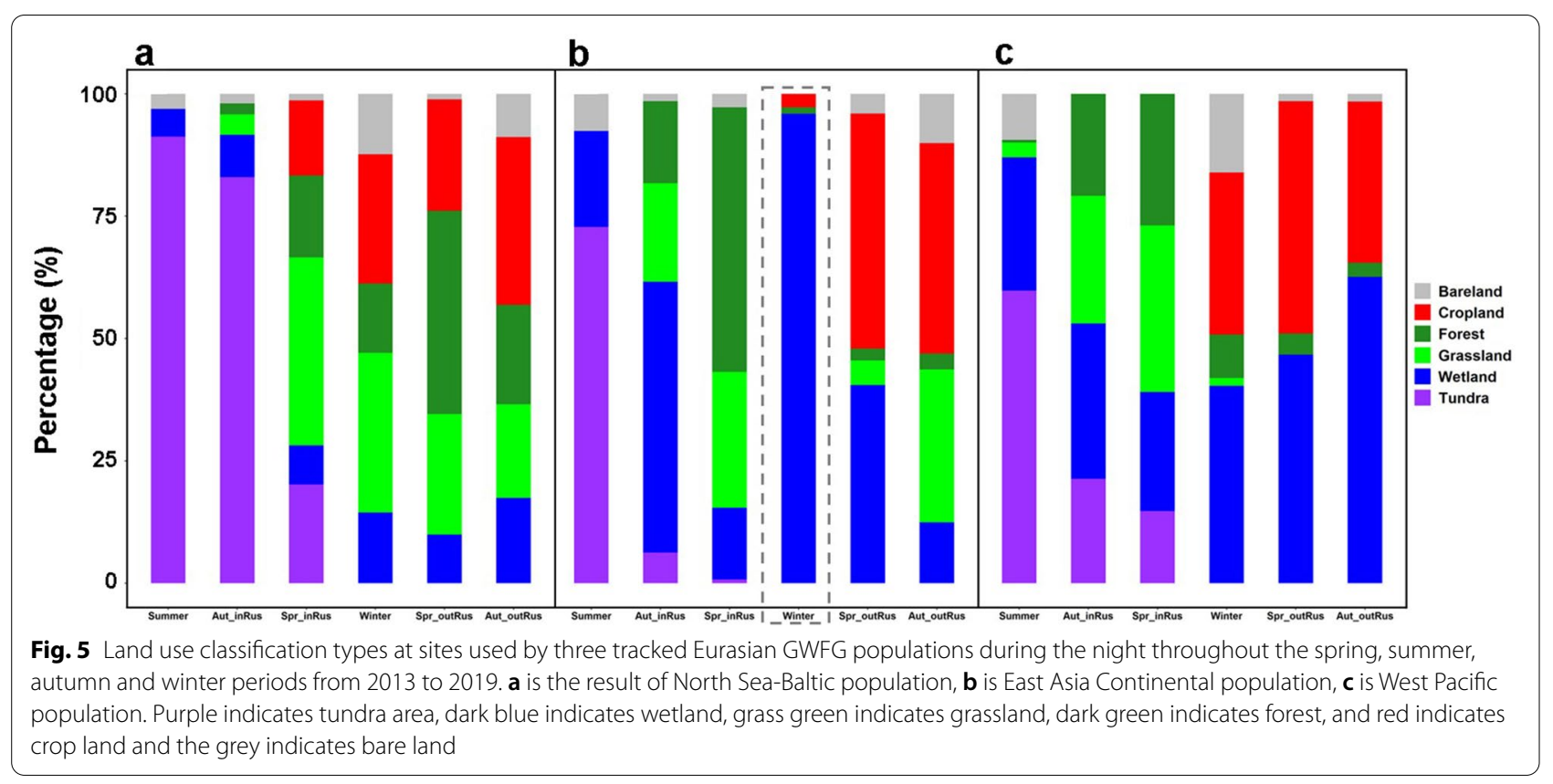

Table 1 Conservation status of three Eurasian GWFG populations in summering, wintering and stopover sites during migration night, the percentage of home range distributed in protected area (the national nature reserves data are used in China, World Database on Protected Areas data set is used outside China)

\begin{tabular}{|c|c|c|c|c|c|c|c|c|}
\hline Population & Item & Summer & Autumn_inRUS & $\begin{array}{l}\text { Autumn } \\
\text { outRUS }\end{array}$ & Winter & Spring_outRUS & Spring_inRUS & Total \\
\hline \multirow{4}{*}{$\begin{array}{l}\text { North Sea-Baltic population } \\
(N=18)\end{array}$} & Protected range $\left(\mathrm{km}^{2}\right)$ & 631 & 201 & 235 & 4190 & 1867 & 169 & 7294 \\
\hline & Home range $\left(\mathrm{km}^{2}\right)$ & 2692 & 2046 & 591 & 10,946 & 7498 & 2391 & 26,165 \\
\hline & Percentage (\%) & 23 & 10 & 40 & 38 & $25 \%$ & 7 & 28 \\
\hline & Duration (day) & 2077 & 899 & 133 & 4214 & 735 & 830 & 8888 \\
\hline \multirow{4}{*}{$\begin{array}{l}\text { East Asia Continental popula- } \\
\text { tion }(N=16)\end{array}$} & Protected range $\left(\mathrm{km}^{2}\right)$ & 5583 & 4 & 1550 & 1031 & 3824 & 565 & 12,557 \\
\hline & Home range $\left(\mathrm{km}^{2}\right)$ & 8383 & 12 & 4799 & 1994 & 15,165 & 1057 & 31,410 \\
\hline & Percentage (\%) & 67 & 35 & 32 & 52 & 25 & 53 & 40 \\
\hline & Duration (day) & 2292 & 14 & 490 & 2931 & 1056 & 308 & 7091 \\
\hline \multirow[t]{4}{*}{ West Pacific population $(\mathrm{N}=44)$} & Protected range $\left(\mathrm{km}^{2}\right)$ & 3885 & 19 & 934 & 1250 & 4928 & 267 & 11,282 \\
\hline & Home range $\left(\mathrm{km}^{2}\right)$ & 10,314 & 1645 & 1543 & 7200 & 11,362 & 1421 & 33,486 \\
\hline & Percentage (\%) & 38 & 1 & 61 & 17 & 43 & 19 & 34 \\
\hline & Duration (day) & 3996 & 273 & 712 & 5368 & 783 & 231 & 11,363 \\
\hline
\end{tabular}

$N$ means the number of individuals for each population; "inRUS" and "outRUS" means the stopover sites during migration within Russia and out of Russia respectively

\section{Feeding on natural wetlands in winter in China}

These data also support the contention that Chinese wintering GWFG almost exclusively feed on wetlands in winter, extending the studies of Yu et al. (2017) to other wintering sites than the site of their study, Poyang Lake. Hence, we have more supporting evidence that in the Yangtze River floodplain (now the most important Chinese wintering area for this species), GWFG very rarely feed on farmland (such as adjacent grasslands, winter wheat fields and rice stubbles), despite these being abundant and accessible in the vicinity of the natural wetlands that they presently use. This provides further support for the theory that the geese are unwilling to use such areas because of the threat of persecution and death from local people that has been put forward to explain the absence of farmland feeding among GWFG wintering in China ( $\mathrm{Si}$ et al. 2020; Zhao et al. 2018). 
Table 2 Conservation status of three Eurasian GWFG populations in summering, wintering and stopover sites during migration daytime, the percentage of home rang distributed in protected area (the national nature reserves data is used in China, World Database on Protected Areas data set is used outside China)

\begin{tabular}{|c|c|c|c|c|c|c|c|c|}
\hline Population & Item & Summer & Autumn_inRUS & Autumn_outRUS & Winter & Spring_outRUS & Spring_inRUS & Total \\
\hline \multirow{4}{*}{$\begin{array}{l}\text { North Sea-Baltic popula- } \\
\text { tion }(N=18)\end{array}$} & Protected rang $\left(\mathrm{km}^{2}\right)$ & 59 & 700 & 3884 & 8947 & 1112 & 91 & 14,793 \\
\hline & Home range $\left(\mathrm{km}^{2}\right)$ & 630 & 2821 & 15,310 & 32,916 & 10,618 & 2759 & 65,054 \\
\hline & Percentage (\%) & 9 & 25 & 25 & $27 \%$ & 10 & 3 & 23 \\
\hline & Duration (day) & 2077 & 899 & 133 & 4214 & 735 & 830 & 8888 \\
\hline \multirow{4}{*}{$\begin{array}{l}\text { East Asia Continental } \\
\text { population }(N=16)\end{array}$} & Protected rang $\left(\mathrm{km}^{2}\right)$ & 6797 & 96 & 1975 & 1301 & 5706 & 551 & 16,427 \\
\hline & Home range $\left(\mathrm{km}^{2}\right)$ & 9143 & 150 & 6069 & 2744 & 27,714 & 1730 & 47,549 \\
\hline & Percentage (\%) & 74 & 64 & 33 & 47 & 21 & 32 & 35 \\
\hline & Duration (day) & 2292 & 14 & 490 & 2931 & 1056 & 308 & 7091 \\
\hline \multirow{4}{*}{$\begin{array}{l}\text { West Pacific population } \\
(N=44)\end{array}$} & Protected rang $\left(\mathrm{km}^{2}\right)$ & 4266 & 196 & 2900 & 1402 & 7730 & 187 & 16,680 \\
\hline & Home range $\left(\mathrm{km}^{2}\right)$ & 15,653 & 823 & 5895 & 21,218 & 23,339 & 1115 & 68,043 \\
\hline & Percentage (\%) & 27 & 24 & 49 & 7 & 33 & 17 & 25 \\
\hline & Duration (day) & 3996 & 273 & 712 & 5368 & 783 & 231 & 11,363 \\
\hline
\end{tabular}

$N$ means the number of individuals for each population; "inRUS" and "outRUS" means the stopover sites during migration within Russia and out of Russia respectively

\section{Feeding on farmland during migration}

What represents a new finding from the data presented here is the fact that in spring, $58 \%$ of daytime registrations outside of Russia of GWFG marked in the East Asia Continental population were from farmland (53\% at night). Furthermore, during autumn staging outside of Russia, East Asia Continental tagged GWFG were registered no less than $73 \%$ from within farmland $34 \%$ at night). This is the first collated evidence to show that the same individuals that avoid using farmland in winter in China readily do so on their spring and autumn staging areas, mostly in northeast China. In this sense they show little difference in their use of grasslands and croplands outside of Russia at these times of year compared to tagged birds from the North Sea-Baltic population (59\% autumn and $66 \%$ spring use of these habitats) and those from the West Pacific population (65\% and $60 \%$, respectively). Hence, these individual Chinese wintering GWFG not only have knowledge of feeding on farmland, but do so to a major degree during their migratory stopovers in northeast China, where they often use natural wetlands for safe night time roosts (consistent with the results of $\mathrm{Si}$ et al. (2018)). For this reason, we can be more confident that it is not the lack of a learned behavioural trait that inhibits their use of grassland and croplands in the Yangtze River floodplain, but more to do with the nature and human use of these habitats on their winter quarters. One effect of this response is that wintering Chinese GWFG, regardless of their precise wintering resort, remain dependent upon natural wetlands for their foraging, which we know to be of variable extent and quality (Aharon-Rotman et al. 2017; Fan et al. 2020). This is in clear contrast to feeding on agricultural crops and waste elsewhere, where they are known to maintain high rates of nutrient and energy acquisition (Amano et al. 2004; Fox and Abraham 2017), and where goose populations exploiting these resources have shown coincident large increases in population size (Fox and Madsen 2017; Cunningham et al. 2020).

\section{Reasons for farmland avoidance in winter in China}

It remains unclear precisely why Chinese GWFG are reticent to go to cropland on the wintering grounds in the Yangtze, but the fact that other sympatric wintering goose species also choose not do so when they also benefit from using farmland outside of China may be instructive. Zhao et al. (2018) suggested that the main reason is that the per capita arable land area is restricted in the Yangtze River floodplain of China, and the high-intensity use of these areas and the resultant levels of human activity and possibly persecution prevent the geese from foraging there. Dense aggregations of domestic ducks and geese gleaning waste wheat and rice grains from stubble also compete directly with wild geese for this resource in the immediate vicinity of wetland nature reserves (Zhao et al. (2018). Certainly, Si et al. (2018) found that the intensity of human disturbance in the Northeast China Plain (where GWFG and Bean Geese Anser fabalis stage in spring and autumn and where they readily use farmland) is much lower than that in the Yangtze River floodplain, but more evidence from multiple sites is needed to support such hypotheses.

\section{Comparison of extent of site safeguard}

Based on the home ranges generated from tracked GWFG from the East Asia Continental population, this 
group of geese were protected the best among these three populations, with $40 \%$ of their used area falling within protected site boundaries by day and $35 \%$ by night (compared to less than 35\% for the European and Korea/Japan wintering populations). Levels of protection were particularly high in summer $(74 \%$ by day, $67 \%$ by night), autumn stopovers within Russia (64\% and $35 \%)$ and on the winter quarters (47\% and $54 \%$ ). Ironically therefore, on the basis of these results, the Chinese wintering GWFG appear to enjoy better site safeguard protection throughout the annual cycle than do the other two populations, yet European and Korea/Japan wintering geese are those showing the greatest and longest increases in abundance (Fox and Leafloor 2018), whereas Chinese GWFG are showing long-term declines (Deng et al. 2020). This may be due to some extent to the fact that Chinese wintering GWFG rarely leave natural wetlands, and by definition, large areas of these are protected because of the severe loss and degradation of wetlands in the Yangtze River floodplain in recent years (Fang et al. 2006).

\section{Agricultural land and protected areas}

Equally, the behaviour of GWFG from the North SeaBaltic and West Pacific populations show a strong propensity to forage on often intensively cultivated arable agricultural land, which inevitably supports relatively little of biodiversity interest, with the result that it rarely enjoys any form of voluntary or statutory protection. China's protected area network is exemplary for its protection of the country's unique biodiversity, but inevitably, the seasonal ephemeral flooding of the Yangtze River floodplain basin wetlands is dependent on the quality and quantity of the water which these protected areas receive from upstream in the catchment, over which the nature reserve management staff have no control. For example, the operation of Three Gorges Dam has led to earlier water recession in autumn at East Dongting Lake. As a result, Carex sedge meadow grew very fast in the warm temperature and became very tall when GWFG arrived during the migration season. Such unsuitable feeding habitat has made GWFG leave this lake (Zhao et al. 2012). Indeed, water abstraction and the extensive creation of dams have all heavily affected the inter-annual hydrodynamics of flooding in the Yangtze, which was always highly variable even before humans had a major influence.

\section{Specialist vs. generalist winter feeding}

By remaining bound to feeding on traditional wetland habitats, the Chinese wintering GWFG is a sedgemeadow specialist, restricted to feeding in areas where this resource is available and abundant. As a result, despite highly effective site protection mechanisms being in place, they cannot guarantee suitable conditions for wintering GWFG in every site in every year, with the result that the species is currently in decline because of lost and degrading habitat quality (Zhao et al. 2012). Many of the nature reserves are continuing to improve the conditions for migratory waterbirds within their boundaries and the recent 10-year ban on all fishing within the Yangtze River protected areas was implemented from January 2020, which will greatly reduce the degree of human disturbance to core areas of the wetlands and to bird species such as GWFG. In contrast, the generalist, farmland-feeding GWFG wintering in Europe and Korea/Japan glean food from farmland, currently without limit in extent and quality and appear not yet limited by ecological space on their breeding areas. This has resulted in these populations benefitting numerically throughout their annual range without a major need for effective site-protection measures.

\section{Additional factors for population dynamics}

Of course, there are many other factors at play in regulating and limiting the abundance of these three GWFG populations. One of the major unknowns remains the extent of traditional hunting activities in Russia in spring and autumn, which are thought to contribute to the relatively high mortality of all three GWFG discussed here during migration. We require more information to quantify this source of mortality (such as instrumenting more geese with loggers to define point and cause of deaths of tracked individuals) and to understand its impact on population growth rate through population modelling and ultimately extend the protected areas networks to include key staging areas, where geese were protected from hunting.

\section{Suggested additional conservation measures}

The migration corridors of the East Asia Continental GWFG are relatively narrow, and the stopover sites are highly concentrated during the migration process. Most of these geese are concentrated in the northeastern plains of China for long-term resting and foraging during both migration episodes (Deng et al. 2019). However, the proportion of the home ranges for our tracked geese that fell within the protected area network in this area was relatively lower than at other times of year. On the basis of our results, we would urge that nature reserves should be added to the list of protected wetlands along the Nenjiang River and the Horqin Left Sandy Land where our results showed that GWFG marked throughout their range concentrated in small areas upon relatively few wetlands, where the population looks especially vulnerable. In addition, the Songnen Plain is the scene of some 
of the most dramatic and rapid wetland habitat loss anywhere in China (Xu et al. 2019), an area also used by GWFG. Wetland degradation results in foraging habitat loss to the geese, which reduces the functionality of their migration network and reduces migration connectivity, features that have undoubtedly contributed to reductions in the population size of Chinese wintering GWFG (Xu and Si 2019).

\section{Conclusions}

These results confirm the need for more strategic planning to effectively protect the East Asian Continental GWFG population to safeguard numbers for future generations. As we have shown, while there is room for improvement, the site protection network in place to protect the species seems adequate yet has failed to stop the declines. As discussed, it was likely due to water abstraction and the creation of dams in the upstream, resulting in change in inter-annual hydrodynamics of flooding and less favourable feeding conditions of the protected areas. The number of buffalos is shown to be positively correlated to the density of GWFG. Indeed, to improve the feeding habitat, buffalo grazing could be used to reduce forage biomass, thereby increasing the availability of more nutritious, newly-grown Carex (Zhang et al. 2015). In addition to create better conditions at protection sites, we have added further evidence to show this population does not use farmland at multiple sites on its winter quarters, yet does so within northeast China during spring and autumn staging, where human disturbance and persecution are said to be less. While we would potentially warn against pushing GWFG (and potentially other geese "trapped" in natural wetlands in the same way) to feed on farmland because of the longer term potential of the species causing potential conflicts with agricultural interests, we cannot help but speculate that if experimental sacrificial, disturbance-free farmland was provided within designated refuge areas adjacent to Yangtze River floodplain wetland reserves as manipulative experiment, this might offer a mechanism to improve the conservation status of this population in years when natural food sources were limited. This seems logical given that, based on our results presented here, the same geese utilize the same agricultural habitats at other points in their annual cycle, so are not learning "bad habits" by exploiting such novel foraging opportunities in winter.

\section{Supplementary Information}

The online version contains supplementary material available at https://doi. org/10.1186/s40657-021-00306-0.

Additional file 1: Table S1. Summary table of Greater White-fronted Geese (Anser albifrons) fitted with solar-powered GPS/GSM or GPS/GPRS telemetry devices 2013-2019 which provided full information on at least one complete spring and autumn migration. Table S2. Percentages of daytime home range falling within different land use types from tagged GWFG from the three populations on their summer and winter quarters and during spring and autumn migration at stopover sites. Table S3. Percentages of nighttime home range falling within different land use types from tagged GWFG from the three populations on their summer and winter quarters and during spring and autumn migration at stopover sites.

\section{Acknowledgements}

We gratefully acknowledge the enormous contributions of the fieldwork teams in China (Fan Lei, Meijuan Zhao, Xin Wang, Qin Zhu, Junjian Zhang, Yuzhan Yang), Russia (Chaun Team: Pavel Kaurov, Anastasia Myl'nikova, Georgy Pavlyukov, Denis Polyakov, Olga Prokopenko, Harald Ris and Sergey Vartanyan; Indigirka Team: Aleksandr Trofimov, Peter Glazov), Germany (Sander Moonen, Association of Dutch Goose Catchers) and the Netherlands (Gerard Müskens, Association of Dutch Goose Catchers).

\section{Authors' contributions}

XD and JZ performed the experiments, analyzed the data, wrote the paper, prepared figures and tables. AK and HK performed the experiments, did the fieldwork, revised the paper. DS, IB and ZX. ZX performed the experiments, did the fieldwork, revised the paper. QZ revised the paper. LC did the fieldwork, conceived and designed the experiments, contributed reagents/materials/ analysis tools. ADF conceived and designed the experiments, revised the paper. All authors contributed critically to the drafts. All authors read and approved the final manuscript.

\section{Funding}

Our study was supported by the National Natural Science Foundation of China (Grant No. 31970433) and China Biodiversity Observation Networks (Sino BON). Tracking of the North Sea-Baltic population was funded by the DLR (ICARUS directive) and the Lower Saxony Ministry of Food, Agriculture and Consumer Protection. The funders had no role in study design, data collection and analysis, decision to publish, or preparation of the manuscript.

\section{Availability of data and materials}

The raw data for this article can be presented for review but cannot be published because waterbirds in the East Asian-Australasian Flyway are highly threatened by illegal hunting and open access of the tracking data will show the critical location and timing of stopovers, which could potentially impact upon the birds greatly in this instance.

\section{Declarations}

Ethics approval and consent to participate

The following information was supplied relating to ethical approvals (i.e., approving body and any reference numbers). The Animal Ethics Committee, Research for Eco-Environmental Sciences, Chinese Academy of Sciences provided full approval for this study. Approval for bird capture and transmitter deployment was obtained from China (the Jiangxi Provincial Forestry Bureau, reference number: Ganlinban 201514, and 201570 and 201647, Anhui Provincial Forestry Bureau, reference number: 2016178), Russia (Federal Service for Technical and Export Control, reference number: No 299, № 334), the Netherlands (Animal Welfare Committee of the Royal Netherlands Academy of Arts and Sciences, DEC NIOO13.14) and Germany (Lower Saxony State Office for Consumer Protection and Food Safety, LAVES AZ 33.19-42502-04-15/1956 dated 15.9.2015).

\section{Consent for publication}

Not applicable.

\section{Competing interests}

The authors declare they have no competing interests.

\section{Author details}

${ }^{1}$ State Key Laboratory of Urban and Regional Ecology, Research Center for Eco-Environmental Sciences, Chinese Academy of Sciences, Beijing 100085, 
China. ${ }^{2}$ University of Chinese Academy of Sciences, Beijing 101408, China. ${ }^{3}$ Department of Migration, Max Planck Institute of Animal Behavior, Radolfzell, Germany. ${ }^{4}$ Institute for Wetlands and Waterbird Research E.V. (IWWR), Verden (Aller), Germany. Institute of Biological Problems of the North, Magadan, Russia. ${ }^{6}$ Institute of Biological Problems of Cryolitozone, Yakutsk, Russia. ${ }^{7}$ Key Laboratory of National Forestry and Grassland Administration On Management of Western Forest Bio-Disaster, College of Forestry, Northwest A \& F University, Yangling 712100, China. ${ }^{8}$ Department of Ecoscience, Aarhus University, Aarhus, Denmark.

\section{Received: 28 February 2021 Accepted: 28 November 2021}

\section{Published online: 09 December 2021}

\section{References}

Abraham K, Jefferies R, Alisauskas R. The dynamics of landscape change and Snow Geese in mid-continent North America. Glob Change Biol. 2005; 11:841-55.

Aharon-Rotman Y, McEvoy J, Zhaoju Z, Yu H, Wang X, Si Y, et al. Water level affects availability of optimal feeding habitats for threatened migratory waterbirds. Ecol Evol. 2017;7:10440-50.

Amano T, Ushiyama K, Fujita G, Higuchi H. Alleviating grazing damage by white-fronted geese: an optimal foraging approach. J Appl Ecol. 2004;41:675-88.

Barraquand F, Benhamou S. Animal movements in heterogeneous landscapes: identifying profitable places and homogeneous movement bouts. Ecology. 2008:89:3336-48.

Bullard F. Estimating the homerange of an animal: a Brownian Bridge Approach. USA: University of North Carolina; 1991.

Bunnefeld N, Börger L, van Moorter B, Rolandsen Christer M, Dettki H, Solberg Erling J, et al. A model-driven approach to quantify migration patterns: individual, regional and yearly differences. J Anim Ecol. 2010;80:466-76.

Calenge C. The package "adehabitat" for the R software: A tool for the analysis of space and habitat use by animals. Ecol Model. 2006;197:516-9.

Cunningham SA, Zhao Q, Weegman MD. Increased rice flooding during winter explains the recent increase in the Pacific Flyway White-fronted Goose Anser albifrons frontalis population in North America. Ibis. 2020;163:231-46.

Deng X, Zhao Q, Fang L, Xu Z, Wang X, He H, et al. Spring migration duration exceeds that of autumn migration in Far East Asian Greater White-fronted Geese (Anser albifrons). Avian Res. 2019;10:19.

Deng X, Zhao Q, Solovyeva D, Lee H, Bysykatova-Harmey I, Xu Z, et al. Contrasting trends in two East Asian populations of the Greater White-fronted Goose Anser albifrons. Wildfowl. 2020;6:181-205.

Edelhoff H, Signer J, Balkenhol N. Path segmentation for beginners: an overview of current methods for detecting changes in animal movement patterns. Movement Ecol. 2016;4:21.

ESRI. ArcGIS Desktop: Release 10.2. Redlands, CA: Environmental Systems Research Institute. 2013.

Fan Y, Zhou L, Cheng L, Song Y, Xu W. Foraging behavior of the Greater Whitefronted Goose (Anser albifrons) wintering at Shengjin Lake: diet shifts and habitat use. Avian Res. 2020;11:3.

Fang J, Wang Z, Zhao S, Li Y, Tang Z, Yu D, et al. Biodiversity changes in the lakes of the Central Yangtze. Front Ecol Environ. 2006;4:369-77.

Fox AD, Abraham KF. Why geese benefit from the transition from natural vegetation to agriculture. Ambio. 2017:46:188-97.

Fox AD, Madsen J. Threatened species to super-abundance: The unexpected international implications of successful goose conservation. Ambio. 2017;46:179-87.

Fox AD, Leafloor JO. A global audit of the status and trends of Arctic and Northern Hemisphere goose populations. Akureyri, Iceland: Conservation of Arctic Flora and Fauna International Secretariat; 2018.

Fox A, Madsen J, Boyd H, Kuijken E, Norriss D, Tombre I, et al. Effects of agricultural change on abundance, fitness components and distribution of two Arctic-nesting goose populations. Glob Change Biol. 2005;11:881-93.

Fox A, Cao L, Zhang Y, Barter M, Zhao M, Meng F, et al. Declines in the tuberfeeding waterbird guild at Shengjin Lake National Nature Reserve, China - a barometer of submerged macrophyte collapse. Aquatic Conserv Mar Freshwater Ecosyst. 2011;21:82-91.
Fox AD, Elmberg J, Tombre IM, Hessel R. Agriculture and herbivorous waterfowl: a review of the scientific basis for improved management. Biol Rev. 2017;92:854-77.

Gong P, Liu H, Zhang M, Li C, Wang J, Huang H, et al. Stable classification with limited sample: transferring a 30-m resolution sample set collected in 2015 to mapping 10-m resolution global land cover in 2017. Sci Bull. 2019;64:23-6.

Horne JS, Garton EO, Krone SM, Lewis JS. Analyzing animal movements using Brownian Bridges. Ecology. 2007:88:2354-63.

Jia Q, Koyama K, Choi C-Y, Kim H-J, Cao L, Gao D, et al. Population estimates and geographical distributions of swans and geese in East Asia based on counts during the non-breeding season. Bird Conserv Int. 2016:26:397-417.

Kim MK, Lee S-I, Lee SD. Habitat use and its implications for the conservation of the overwintering populations of Bean Goose Anser fabalis and Greater White-Fronted Goose A. albifrons in South Korea. Ornithol Sci. 2016;15:141-9.

Kölzsch A, Müskens GJDM, Kruckenberg H, Glazov P, Weinzierl R, Nolet BA, et al. Towards a new understanding of migration timing: slower spring than autumn migration in geese reflects different decision rules for stopover use and departure. Oikos. 2016;125:1496-507.

Lavielle M. Using penalized contrasts for the change-point problem. Signal Process. 2005;85:1501-10.

Le Corre M, Dussault C, Côté SD. Detecting changes in the annual movements of terrestrial migratory species: using the first-passage time to document the spring migration of caribou. Movement Ecol. 2014;2:19.

Mohr CO. Table of equivalent populations of North American small mammals. Am Midland Nat. 1947;37:223-49.

Powell R. Animal home ranges and territories and home range estimators. In: Pearl MC, Boitani L, Fuller TK, editors. Research techniques in animal ecology: controversies and consequences. USA: Columbia University Press; 2000. p. 64-110.

Shimada T. Daily activity pattern and habitat use of Greater White-fronted Geese wintering in Japan: Factors of the population increase. Waterbirds. 2002;25:371-7.

Shimada T, Mizota C. Fluctuation in food resources for, and crop damage by, Greater White-fronted Geese in relation to agriculture in Japan. Japn J Ornithol. 2011;60:52-62.

Si Y, Xu Y, Xu F, Li X, Zhang W, Wielstra B, et al. Spring migration patterns, habitat use, and stopover site protection status for two declining waterfowl species wintering in China as revealed by satellite tracking. Ecol Evol. 2018;8:6280-9.

Si Y, Wei J, Wu W, Zhang W, Hou L, Yu L, et al. Reducing human pressure on farmland could rescue China's declining wintering geese. Movement Ecol. 2020;8:35.

Team RDC. R: A language and environment for statistical computing. R Foundation for Statistical Computing. Vienna, Austria; 2017.

Wang X, Cao L, Bysykatova I, Xu Z, Rozenfeld S, Jeong W, et al. The Far East taiga forest: unrecognized inhospitable terrain for migrating Arctic-nesting waterbirds? Peer J. 2018;6:e4353.

$\mathrm{Xu}$ F, Si Y. The frost wave hypothesis: How the environment drives autumn departure of migratory waterfowl. Ecol Indicat. 2019;101:1018-25.

Xu W, Fan X, Ma J, Pimm SL, Kong L, Zeng Y, et al. Hidden loss of wetlands in China. Curr Biol. 2019;29:3065-71.e2.

Yu H, Wang X, Cao L, Zhang L, Jia Q, Lee H, et al. Are declining populations of wild geese in China 'prisoners' of their natural habitats? Curr Biol. 2017:27:R376-7.

Zhang Y, Jia Q, Prins HHT, Cao L, de Boer WF. Individual-area relationship best explains goose species density in wetlands. PLoS ONE. 2015;10:e0124972.

Zhao M, Cong P, Barter M, Fox AD, Cao L. The changing abundance and distribution of Greater White-fronted Geese Anser albifrons in the Yangtze River floodplain: impacts of recent hydrological changes. Bird Conserv Int. 2012;22:135-43.

Zhao Q, Wang X, Cao L, Fox AD. Why Chinese wintering geese hesitate to exploit farmland. Ibis. 2018;160:703-5. 